\title{
Ethnicity as a Historical Process: AnAppraisal on Patterns of Ethnogenesis in Nepal
}

\author{
Dr. Pradeep Acharya*
}

\begin{abstract}
Ethnicity is a social and historical process, which carries changes and continuity simultaneously in different dimension of ethnic identity among the ethnic groups. Historical forces in terms of their social, political and economic dimension shape how ethnic identity is defined and created as well as recreated in contemporary society. Given the discussion this paper focuses on how the members of an ethnic group define themselves as a social group over time according to the social and political field in which they are in. The study has aims to describe the historical chronology of the transformation of Pahari identity over time in Nepal. Further, the paper particularly attempted to see how the political system of the country shapes the creation and recreation of identity among the members of the given ethnic group. The study is based on primarily on number of in-depth interviews of the members of the given ethnic community living in middle hills in and around around Kathmandu valley accompanied by available empirical literatures on ethnicity based on Nepal and abroad. The paper concludes that ethnicity and ethnic identity are not a stable entity rather it transforms as per social and political environment of the contemporary society.
\end{abstract}

Keywords: Ethnicity, Ethnic Identity, History and Democracy.

\section{Introduction}

This paper has attempted to illustrate that Pahari culture has never been a rigid and stable institutional structures, instead they are fluid and flexible cognitive structures. Not only among the Paharis, this fact can be said to be true for ethnic groups of Nepal, for instance, in case of the Thakali of Nepal, Fisher (2001) asserts that they have fluid boundaries, which, are continually reinvented and modified without being totally transformed. In fact, cultures in general, and Pahari culture in particular, have always continued what they already were, which also changed as they adjusted with their neighborhood society and constructed their histories and practices up to present. Furthermore, in a reviews of number of studies regarding "ethnogenesis" outside Nepalese context, Blanton (2015), has been able to identify ethnic construction as a productive path to enhancing cooperation in the challenging contexts and as a result of building local-scale ethnic group building in chaotic condition of ethnic identity.

*Dr.Acharya is a Lecturer of Anthropology, CNAS, T.U., email: pradeep@cdsatu.edu.np 
'Ethnicity', like most other concepts, not only in anthropology but in many other social sciences, has connection with the 'past' - firstly, as a tradition or the cultural past; second, as history or a record of key events; third, the past as myth; and finally, the past as a resource for the present (Eller, 1997). Ethnicity is not a stable phenomenon, rather, it is dynamic over time, therefore without the knowledge of historical facts and contexts, the study of ethnicity becomes futile, which is also highlighted by Gellner (2001), who has proposed five basic rules, one of them is - nationalism and ethnicity should be studied in the historical context. Similarly, Nagel (1994), has emphasized identity and culture as two of the basic building blocks of ethnicity, which is best understood as a dynamic, constantly evolving property of ethnic categories of both individual and the group that is shaped and reshaped in the given social, economic, and political processes.

The course of construction of group identity and resuscitation or persistence of cultural features of a people undergoing rapid and radical change is understood as the process of ethnogenesis. The concept itself comes from the Soviet Union where scholars and ideologues constantly confront the underpinnings of cultural persistence and social consciousness of 'being' Lithuanian, Latvian, Ukranian etc. The concept of ethnogenesis may also be applied to the overcoming of certain ethnic boundaries those constructed on political, dialect or ecosystem bases and affirming the oneness of a people according to a given criterion (Seymour-Smith, 1986). Given the context, this paper aims to shed light on the phenomenon of ethnogenesis among thePahari community, one of the listed nationalities of Nepal in terms of the dynamics of ethnicity among the given social group.

\section{Cultural Dimension of Ethnic Boundaries}

One of the remarkable visible cultural markers that makes Paharis distinct from other groups, particularly, the neighboring group Newars, is their scattered rural settlement pattern, unlike easily distinguishableNewar's urban character comprising red brick, three or more storeyes, tightly packed narrow streets and alleys etc (Quigley, 1987). It is rather more, subjective feeling including objective ones mentioned above, i.e. the subjective feeling of 'different-ness' based on less observable markers (e.g. mythology, oral history etc) in the case of Pahari ethnogenesis.

The Paharis of Nepal, who have been historically categorized as similar to or sometime belonging to bigger neighboring groups like Newar and Tamangs, and living around the middle hills of Nepal were less familiar among fellow members until recently. Moreover, the boundary or the distinctions created and maintained between Pahari versus Nagarkoti, which prevailed for a long time marked by distinctness of identity, Nagarkoti being understood as one of the Newar category, later after the provision of inclusive 
privileges provided by the state, were again attempted to merge, so that the distinction is clear. This fact reflects the phenomenon of political salience of fluid boundaries. In addition, another aspects of cultural markers is the Pahari mother tongue, which is not comprehended by many members. Therefore, it can be said that, if language comprehension and use were strong among the Paharis, the boundary would have been stronger, as it facilitated communication inside the group hindering communication toward outside. Social closure is of less degree, i.e. boundary had been crossed either easily to get rid of stigma or to have access for resources such as job opportunities, particularly those provided by the state.

The topography of thePahari settlement, the structure of their houses and more or less the size of the cluster looks like similar with each other, typically reflecting the appearance of most of the human settlement around the hills of Nepal - houses with animal shed by the side, non-irrigated field with some trees around as well as irrigated field with crops by the river in valleys were all similar which could be in no way pinpointed to be a typical Pahari settlement. The rugged hilly topography, remoteness of transport, electricity, and communicationare the characteristic features of most of the settlements except some. Similarity in the outlook of the settlement in terms of topography, living conditions, housing patterns, there aredissimilarpatterns of culture (particularly ritualistic observations), language and linguistic comprehension, ancestry of clans of origin and some variation in mythology too. The villages in the either side of the same hill have variation in language comprehension. One prominent difference worthy mentioning here are the clan names, which is quite different as per the neighborhood ethnic groups in their vicinity. This is how the Pahari communities of Nepal show the characteristics of similarities and differences from one hilltop to the other. The similar living conditions, similar topographical locations, the same ethnonym, different variation of similar mythology etc were accompanied by different language, differential linguistic comprehension, distinct clan names and ancestry as well as varied ancestral worship rituals etc. The Pahari of Nepal which is different from other ethnic groups in terms of various markers, simultaneously showing various similarities with larger neighboring groups are characterized by many intra-group variations but at the same time same umbrella like ethnonym and similar mythology of origin of nomenclature. As Jenkin (2001), has proposed social constructionist model of ethnicity - ethnicity is based on dialectic interplay of similarities and difference. Regardless of any unique and typically observable different markers, except some symbolic and micro-ritualistic variance, Paharis of Nepal, as Barth (1969) has stated the concept of "self-ascription and ascription by others", are understood as a different group by Pahari themselves and neighboring groups around Kabhrepalanchok and Sindhupalchok, except some scholarly proposition about the Paharis belonging to Newar internal caste hierarchy, particularly by Nepali (1965) with 
reference to Hofer (1997, 2004) as well as Gellner's (1997) speculation about possible historical connectedness between Pahari, Rajbahak of Newar and the Jyapu's of Pyangaun.

\section{The Present Context}

The history of Pahari ethnicity appears to be comprised of stigmatization, exclusion and marginalization wherein a group adapted to the changing circumstances brought on by the social forces. The Pahari case demonstrates that ethnicity is not an inherent quality that is simply passed on from generation to generation; it is a dynamic process of interaction and adjustment in the contemporary social and historical context.

Paharis in different parts (around traditional locations) of the country as a segregated cluster seemed to differ regarding some of their markers of categorization, i.e. clan, caste, surname, origin etc. For example, Paharis of Lalitpur are divided into different clusters like Badikhel, Chhampi, Lele etc; furthermore, in Lele too, Sikharpa and Pare are two clusters. In the same way, around Khopasi, though the patterns of clans etc are similar, they are distributed in clusters like Tallo Gaun, Mathlo Gaun, Dangghat etc. The administrative division of the country has nothing to do with the cluster division of the Paharis; rather, their clusters are purely local and spatial i.e. geographical, where Paharis are living as a separate group from many generations. Therefore, the impression is one of systematically branching segmentary groups of descent but a closer study revealed that this is true for clusters living spatially nearby. What I mean to say is that, if we compare the observations among the Paharis of Badikhel and Thokarpa, we can have number of objective markers of differentiation regarding ancestory, rituals, and language etc as well as the acculturated or otherwise resemblances with major neighboring groups, like Tamang around Thokarpa and adjacent villages or clusters and Newar around Badikhel and adjacent areas. It was seen in the first place that it is not at all clear how comprehensive this spatial connection depicting similarities and differences is. On the uppermost level we found that the category of the Tibeto-Burman (i.e. racial), a quite evocative and relatively vague category, which encompass almost indigenous nationalities of Nepal. Still, it is what can most readily be termed the unit of overarching 'indigenous' identity, as expressed particularly in the preference of reciprocal marriages within the given umbrella ethnonym of Pahari. Furthermore, it became clear that the Pahari are subdivided into a number of groupings of various sizes, some of which are relatively artificial and of recent historical origin. For example, the male duck sacrificing clan in Badikhel are very small in size that it is difficult for them to find eligible mate for marriage as per cultural prescription. Thus the Pahari as a specific ethnic group has existed for a long time in different parts of Nepal but unifying ancestral link is very difficult to be identified. However, in the thinking of the 
Paharimembers, as reflected in the mythological narrative, represent one of the excluded hilly groups in the history of Nepal.

The territorial ties among groups are also seen to be most recent ones; however, it can be attributed to the geographical distance, which obviously influences the intensity and frequency of contact, familiarity and alliance. For instance, a Pahari of Lalitpur and another from Ramechhap, of course, had difficulty connecting because of spatial distances and lack of means of communications and mass medias so far. Prior to the initiation for institutionalization of ethnic association, these groups included under the umbrella ethnonymPahari as one of the listed nationalities of Nepal, were living as a separate group with the name Pahari, however, with some disguise and some disgruntlement and socioeconomic marginality around these localities, who had none or only very small awareness about the existence of fellow group members elsewhere in Nepal. More clearly, the Paharis of Lalitpur did not have idea about the Paharis of Ramechhap, though they were aware of the fellow Paharis nearby. Only after that, by the effort of few activists, Pahari ethnic consciousness was raised toward building a solidarity only one and half decades back.

\section{Concluding Remarks}

The discussion made in the preceding paragraphs clearly shows that the pathway of Pahari ethnogenesis can be said to have following the pattern of history of contemporary society which usually goes through a multilevel process of creating consciousness and maintenance of solidarity of members by some active individuals within the domain of given historical facts regarding cultural markers. Simultaneously, social construction of ethnic identic seem to be variable in the historical context, however, with continuity of some subjective and objective traits, i.e. sometimes expansion and at times repositioning of the group identity.

It is apparent that the process is the result of various social structural factors such as historical, political, and economical. Moreover, the political change, i.e. restoration of multiparty democracy resulting in the favorable environment for creating formal ethnic association has been found to be instrumental in the recreation and maintenance of Pahari ethnic identity. Only after this, the Paharis have been able to develop territorial ties among fellow members living in different areas resulting in the transformation of identity. In short, ethnicity and ethnic identity are not a stable entity rather it transforms as per social and political environment of the contemporary society. 


\section{References}

Barth, F. (1969). Ethnic Groups and Boundaries, the social organization of cultural difference. Little Brown and Co., Norway

Blanton, R.E. (2015). Theories of ethnicity and the dynamics of ethnic change in multiethnic societies. Proceedings of the National Academy of Sciences of the United States of America, 112(30), pp.9176-9181.

Eller, J.D. (1997). Ethnicity, Culture, and "The Past". Michigan Quarterly Review, 36(4).

Fisher, W. (2001). Fluid Boundaries, forming and transforming identity in Nepal. Columbia University Press, USA.

Gellner, D. (1997). Caste, Communalism and Communism, Newars and the Nepalese State. Nationalism and Ethnicity in a Hindu Kingdom; The Politics of Culture in Contemporary Nepal. Gellner, D.N., Plaff-Czarnecka, J., Whelpton, J. edited. Hardwood Academic Publishers, Netherlands

Gellner, D. (2001). How should one study ethnicity and nationalism. Contribution to Nepalese Studies, Vol.28, No.1, January, CNAS, TU.

Hofer, A. (2004). The Caste Hierarchy and the State of Nepal: A study of the Muluki Ain of 1854. Originally published in 1979. Himal books, Nepal

Jenkins, R. (2001). Ethnicity: Anthropological Aspects. International Encyclopedia of the Social \& Behavioral Sciences, edited by Smelser, N.J., Baltes, P.B., Elsevier Science Ltd, pp. 482428

Nagel, J. (1994). Constructing Ethnicity: Creating and Recreating Ethnic Identity and Culture. Social Problems. Special Issue on Immigration, Race, and Ethnicity in America, 41(1), pp. 152176.

Nepali, G.S. (1965). The Newars. United Asia Publications, Bombay, India, 1965

Quigley, D. (1987). Ethnicity without Nationalism, the Newars of Nepal. European Journal of Sociology. pp.152-170

Seymour-Smith, C. (1986). Macmillan Dictionary of Anthropology. London:Macmillan.

Wimmer, A. (2008). The Making and Unmaking of Ethnic Boundaries, a Multilevel Process Theory. American Journal of Sociology, 113(4), pp.970-1022. 